\title{
Sinus arrhythmia in children with atrial septal defect: an analysis of heart rate variability before and after surgical repair
}

\author{
JOHN P FINLEY, SHERWIN T NUGENT, * WIEBKE HELLENBRAND, M CRAIG, \\ D A GILLIS
}

From the Department of Pediatrics, Izaak Walton Killam Hospital for Children, and Dalhousie University, and Department of Physics, Dalhousie University, Halifax, Novia Scotia, Canada

SUMMARY The expression of sinus arrhythmia depends on separation of the systemic and ${ }^{\circ}$ pulmonary venous return to the heart as well as on normal autonomic control mechanisms. Patients $ᄋ$ with atrial septal defect provide a naturally occurring experiment of communication between the two venous systems. In adults with atrial septal defect sinus arrhythmia is minimal or absent. But children with atrial septal defect retain appreciable sinus arrhythmia, although this is not $\hat{\sim}_{3}$ recognised in published reports. To understand why this is so, continuous electrocardiograms were recorded before and after operation in 10 children (aged 4-16 years, mean 6.3) with atrial septal defects and in 10 normal children (aged 5-7 years, mean 6.1). Mean RR intervals were calculated for periods of one minute, and the standard deviation was used as an index of heart rate variability (that is sinus arrhythmia). Frequency analysis (spectral analysis) was also performed on a continuous beat to beat record of heart rate to describe the frequency components that may reflect autonomic activity. The results confirmed the presence of considerable sinus arrhythmia in children with unoperated atrial septal defect. None the less, the standard deviation of RR intervals $\stackrel{2}{\Rightarrow}$ in the children with unoperated atrial septal defect was significantly less than that for the normal $\frac{\circ}{3}$ children, and variation increased after closure of the defect. Power spectral analysis of $\supset$ instantaneous heart rate indicated that the high frequency $(0 \cdot 15-0.45 \mathrm{~Hz})$ vagally mediated component of variability was lower for patients than for controls which may indicate abnormalities $\vec{D}$ of autonomic control of heart rate in these children. The comparative retention of sinus arrhythmia in children with atrial septal defect may relate to the small size of the right atrium or differences in myocardial compliance compared with adults.

Respiratory sinus arrhythmia is a normal feature of healthy individuals. Its presence depends on normal autonomic control of the heart and normal cardiac anatomy. Atrial septal defect is said to be characterised by decreased sinus arrhythmia or heart rate variability in adults ${ }^{1}$ but this has not been proved in children. Our clinical observations (fig 1) did not suggest that a decrease in the variability of heart rate is characteristic of children with atrial septal defect.

This study was designed to compare heart rate variability in children with atrial septal defect before

Requests for reprints to Dr John P Finley, Department of Cardiology, The Izaak Walton Killam Hospital for Children, 5850 University Avenue, Halifax, Novia Scotia, Canada B3J 3G9.

Accepted for publication 8 November 1988 and after operation, and to compare their variability with that of normal children. We also used frequency analysis (power spectral analysis) of the heart rate of these children to describe the frequency components in their heart rate variability that reflect autonomic $\Omega$ activity and to examine the possible effects of closure $N$ of the atrial septal defect on autonomic regulation of $\mathrm{N}$ the heart rate.

\section{Patients and methods}

We studied 20 children: 10 normal children aged five to seven (mean 6.1), and 10 aged four to 16 (mean 6.3) with atrial septal defect who were about to undergo operation. All patients with atrial septal defect were symptom free or had minimal symptoms, and clinical 

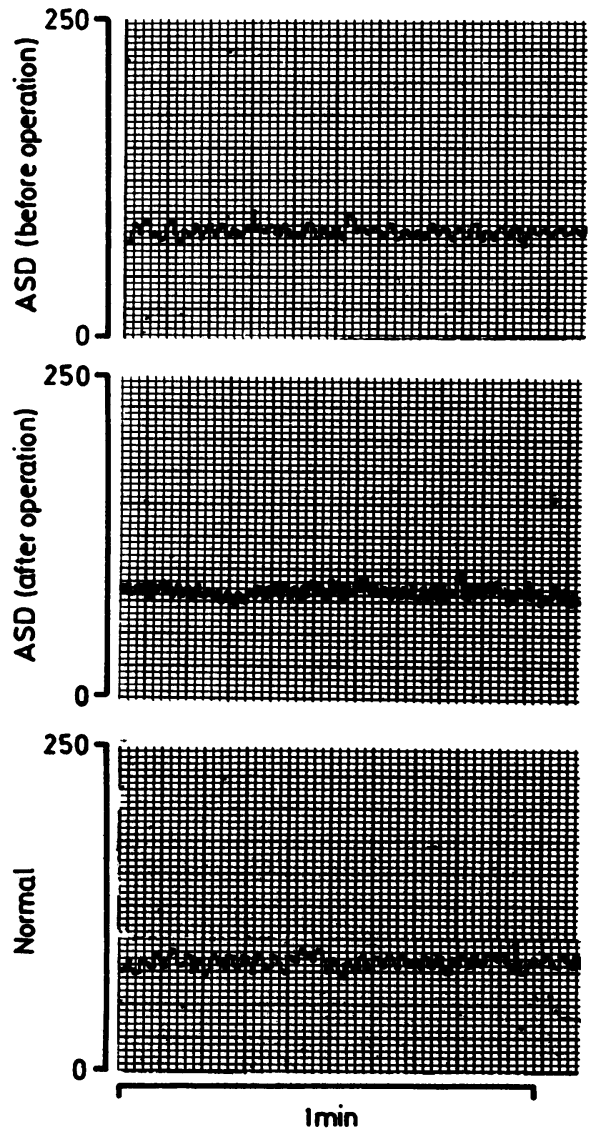

Fig 1 Instantaneous heart rate in a normal child and in a child before and after surgical closure of an atrial septal defect.

findings included a systolic murmur, a wide fixed split of the second heart sound, cardiomegaly on chest $x$ ray, and right ventricular hypertrophy on electrocardiograph. Echocardiography confirmed the diagnosis of atrial septal defect in all. Cardiac catheterisation was performed in six patients and in these the pulmonary:systemic flow ratios ranged from 2.0 to 3.2 (mean 2.5 ). The defect was confirmed at operation in all cases: nine had isolated secundum atrial septal defect and one had a primum defect. The heart rate was recorded immediately before operation and 4.9 (2) months afterwards. All children had normal sinus rhythm.

We recorded heart rate and respiratory activity from electrocardiographic and impedance respiratory signals obtained from a Healthdyne apnoeabradycardia monitor (model 16000-01). The electrocardiogram was converted to beat to beat heart rate by an analogue device ${ }^{2}$ during simultaneous recording at a slow speed on paper and FM tape. A
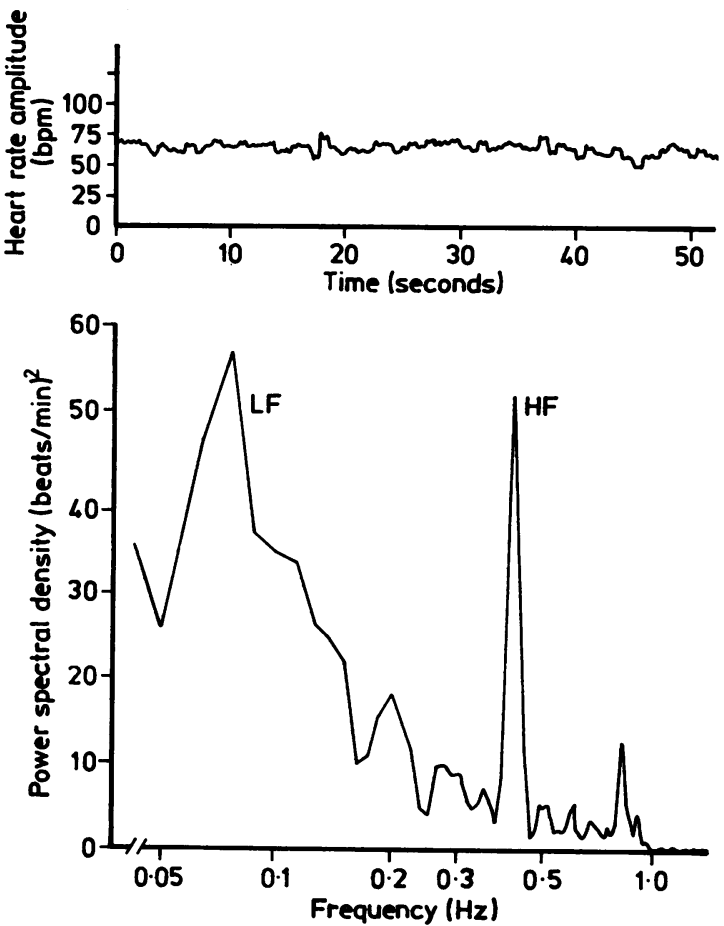

Fig 2 Instantaneous heart rate and corresponding power spectral density of subject showing prominent low frequency and high frequency peak.

brief initial period of familiarisation ensured that all the children were at ease with the apparatus. Children were asked to remain quiet but awake during the recordings, which lasted 10-15 minutes in total and were performed with the child standing and supine. We used both positions to evaluate two levels of autonomic tone: standing, high sympathetic and low parasympathetic; supine, low sympathetic and high parasympathetic tone.

We stored heart rate data for a one minute period for each position on a computer disc for subsequent analogue-digital conversion (rate $250 \mathrm{~Hz}$ ) and processing. For computerised detection of the $\mathbf{R}$ wave we used the procedures of Wolf et al ${ }^{3}$ followed by human editing and data correction as described previously." The mean $R R$ interval and standard deviation were computed for each posture for each patient.

In a separate analysis, a three to four minute segment of continuous stationary heart rate data for each position was processed by spectral analyser (Nicolet No 660A) according to previously published technique. ${ }^{2}$ We selected a segment from the paper recording that was free of sudden changes in the respiratory activity such as sighs or movement 
Table 1 Group mean (SEM) RR intervals and standard deviations of $R R$ intervals (ms) for subjects in supine and upright positions

\begin{tabular}{|c|c|c|c|}
\hline & No & $R R$ & $S D$ \\
\hline $\begin{array}{l}\text { Supine: } \\
\text { Atrial septal defect (preop) }\end{array}$ & 9 & \multirow{3}{*}{$\begin{array}{c}658 \\
(184) \\
739 \\
(81) \\
702 \\
(96)\end{array}$} & \multirow{3}{*}{$\begin{array}{c}28 \cdot 4 \\
(21 \cdot 3) \\
48 \cdot 7^{\star} \\
(15 \cdot 2) \\
72 \cdot 4^{\star} \\
(36 \cdot 8)\end{array}$} \\
\hline Atrial septal defect (postop) & 10 & & \\
\hline Control & 10 & & \\
\hline $\begin{array}{l}\text { Upright: } \\
\text { Atrial septal defect (preop) }\end{array}$ & 9 & \multirow{3}{*}{$\begin{array}{c}591 \\
(88) \\
628 \\
(54) \\
610 \\
(77)\end{array}$} & \multirow{3}{*}{$\begin{array}{c}31.4 \\
(14.9) \\
(35.6) \\
(12.3) \\
47.2 \dagger \\
(15.0)\end{array}$} \\
\hline Atrial septal defect (postop) & 10 & & \\
\hline Control & 10 & & \\
\hline
\end{tabular}

${ }^{\star p}<0.01 v$ preop, $+\mathrm{p}<0.04 v$ preop.

artefact. The power associated with the low frequency and high frequency peaks was determined as the square root of the area under each peak within $0.025 \mathrm{~Hz}$ of the low frequency peak and within 0.050 $\mathrm{Hz}$ of the high frequency peak (fig 2). Area ratios L:H were calculated.

Because the data were not normally distributed they were logarithmically transformed before being compared by two tailed $t$ tests.

The research protocol was approved by the hospital ethics committee and informed consent was obtained from the children's parents.

\section{Results}

ANALYSIS OF THE RR INTERVAL

In both the supine and standing positions the mean $R \mathbf{R}$ intervals before operation and after operation in those with an atrial septal defect and in the controls were not statistically different (table 1 ). There was, however, a tendency for the RR interval to increase (decreased heart rate) after operation in the group with an atrial septal defect.

Heart rate variability in the supine position, as measured by the standard deviation of the $R R$ interval, was significantly less before operation in those with atrial septal defects than in the controls $(28.4 v 72.4 \mathrm{~ms}, \mathrm{p}<0.01)$, with very little overlap between the groups (fig 3 ). Also, the heart rate variability significantly increased after closure of the atrial septal defect $(28.4 v 48.7 \mathrm{~ms}, \mathrm{p}<0.01)$. Although the results after operation overlapped with those of both the preoperative and control groups, the standard deviation of $R R$ intervals increased after surgical repair in all but the oldest patient. The standard deviation after operation was not significantly different from that of the control group.

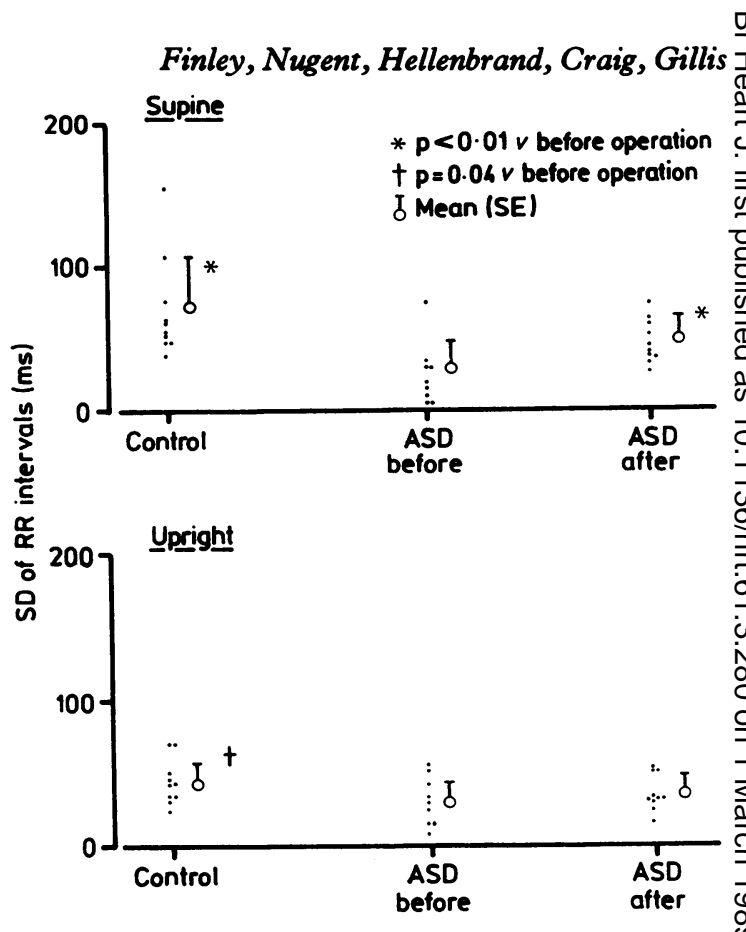

Fig 3 Standard deviation of $R R$ intervals while individual is supine or upright of controls and of children before and after surgical closure of an atrial septal defect.

In the upright position the standard deviation of the $R R$ intervals was also significantly lower before operation in those with an atrial septal defect than in $\vec{\circ}$ controls ( $31.4 v 47.2 \mathrm{~ms}, \mathrm{p}<0.05)$, but it was not 3 changed after surgical repair. There was no difference in respiratory rate between the three. groups in either position.

\section{SPECTRAL ANALYSIS OF BEAT-TO-BEAT HEART RATE}

Heart rate variability was also assessed by spectrah analysis. In both supine and upright positions there was considerable variation in the amplitude values (table 2, fig 4). In the supine position, those with? atrial septal defects showed an increase of low frequency amplitude and of $\mathrm{L}: \mathrm{H}$ after operation These changes were not statistically significant $N_{0}^{N}$ however. There was a decrease in high frequencyn amplitude which also did not reach significance N Control values were generally slightly higher than values before and after operation, significantly so in the case of high frequency ( $\mathrm{p}<0.03 v$ preoperative values, $\mathrm{p}<0.01 v$ postoperative values). In all bue one patient, values of $\mathrm{L}: \mathrm{H}$ increased after operation ? Individual low frequency and high frequency values showed no consistent response to operation. Thered was no correlation between changes seen in low? frequency, high frequency, and L:H with operation? 

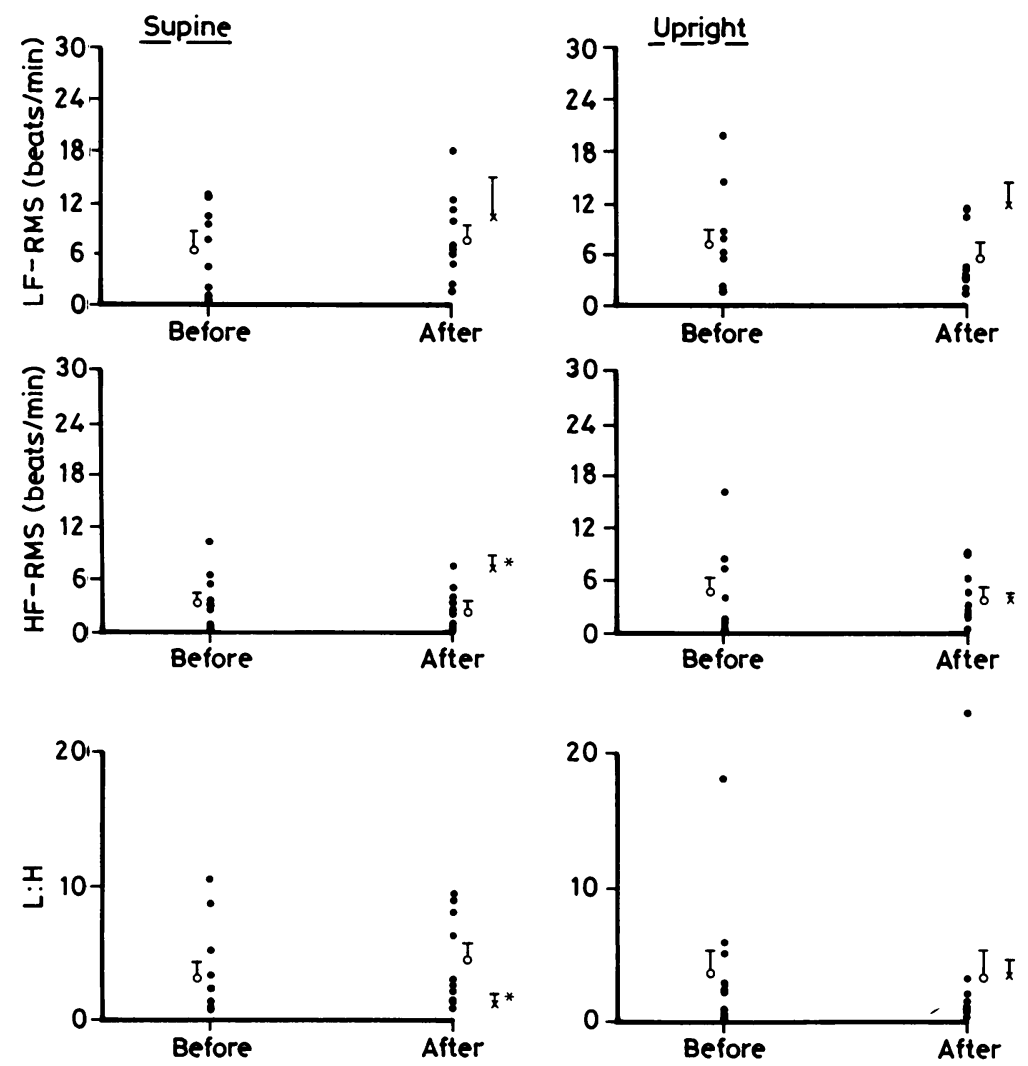

Fig 4 Low frequency and high frequency amplitudes and $L: H$ ratio in supine and upright positions of patients before and after surgical closure of an atrial septal defect. Mean control values are also shown.

I ASD mean (SE) I Control mean (SE)

* $p<0.03 v$ before operation. $p<0.01 v$ after operation

Table 2 Group mean (SEM) low frequency and high frequency spectral rms values (beats/min) and $L: H$ ratio for subjects in supine and upright positions

\begin{tabular}{|c|c|c|c|c|}
\hline & No & $\begin{array}{l}\text { Low } \\
\text { frequency }\end{array}$ & $\begin{array}{l}\text { High } \\
\text { frequency }\end{array}$ & $L: H$ \\
\hline \multicolumn{5}{|l|}{ Supine: } \\
\hline $\begin{array}{l}\text { Atrial septal defect } \\
\text { (preop) }\end{array}$ & 10 & $\begin{array}{l}6.42 \\
1.58\end{array}$ & $\begin{array}{l}3.39 \\
1.04\end{array}$ & $\begin{array}{l}3.50 \\
1.04\end{array}$ \\
\hline $\begin{array}{l}\text { Atrial septal defect } \\
\text { (postop) }\end{array}$ & 10 & $\begin{array}{l}8 \cdot 10 \\
1.57\end{array}$ & $\begin{array}{l}2.88 \\
0.75\end{array}$ & $\begin{array}{l}4.34 \\
1.00\end{array}$ \\
\hline Controls & 10 & $\begin{array}{c}10.5 \\
4.86\end{array}$ & $\begin{array}{l}7 \cdot 62^{\star} \\
1 \cdot 44\end{array}$ & $\begin{array}{l}1.48^{\star} \\
0.45\end{array}$ \\
\hline \multicolumn{5}{|l|}{ Upright: } \\
\hline $\begin{array}{l}\text { Atrial septal defect } \\
\text { (preop) }\end{array}$ & 10 & $\begin{array}{l}7 \cdot 26 \\
1.90\end{array}$ & $\begin{array}{l}4.95 \\
1.63\end{array}$ & $\begin{array}{l}3.92 \\
1.70\end{array}$ \\
\hline $\begin{array}{l}\text { Atrial septal defect } \\
\text { (postop) }\end{array}$ & 9 & $\begin{array}{l}5.91 \\
1.39\end{array}$ & $\begin{array}{l}4 \cdot 43 \\
1.09\end{array}$ & $\begin{array}{l}3.64 \\
1.70\end{array}$ \\
\hline Controls & 10 & $\begin{array}{c}12.0 \\
2.69\end{array}$ & $\begin{array}{l}4.01 \\
0.61\end{array}$ & $\begin{array}{l}3.69 \\
0.95\end{array}$ \\
\hline
\end{tabular}

${ }^{\star} \mathrm{p}<0.03 v$ preop, $\mathrm{p}<0.01 v$ postop.
In the upright position, there was a wider scatter of values with no consistent response with operation.

\section{Discussion}

This study confirms that although there is considerable variability in heart rate in children with atrial septal defect, it is less than that in normal children and that it increases after closure of the defect.

Heart rate variability is known to be greater in young children than in adults ${ }^{56}$; this makes it more difficult to identify children with atrial septal defect. The substantial increase in heart rate variability in children with atrial septal defect compared with adults may be related to the smaller right atrium of children or to differences in ventricular compliance between adults and children. ${ }^{6}$

The fact that heart rate variability (measured by standard deviation of RR intervals) tends to become 
normal after closure of the atrial septal defect suggests that it is dependent on the anatomical change within the heart. The two most important mechanisms producing sinus arrhythmia in normal persons are right atrial stretch with the inspiratory increase in systemic venous return and inspiratory inhibition of the carotid sinus reflex, both of which produce relative tachycardia. ${ }^{7}$ An atrial septal defect dampens the respiratory fluctuations of right atrial volume because there is communication between right and left atria ${ }^{89}$ : further, with the larger right atrium of atrial septal defect, the inspiratory increase of right atrial volume is proportionately less than that occurring with a normal right atrium. This would contribute to diminished variability of the heart rate.

We used spectral analysis to study heart rate variability in these patients because of its potential to identify autonomic abnormalities of heart rate control that could also be responsible for decreased heart rate variability. Heart rate variability in people of all ages has two main frequencies of variation: a high frequency band, $0 \cdot 15-0 \cdot 45 \mathrm{~Hz}$ ( 3 second period) and low frequency band, $0.03-0.15 \mathrm{~Hz}$ (12 second period) ${ }^{610}$ The prominence of these two frequency bands in heart rate variability can be expressed by amplitude in the power spectrum. In general, the high frequency band corresponds to the respiratory frequency and is vagally mediated. ${ }^{111}$ The low frequency peak seems to be mediated by both the sympathetic and parasympathetic systems. ${ }^{1011} \mathrm{~A}$ change in peak amplitude may be caused by changes in coupling between respiration and the heart or changes in autonomic control.

When the children were supine, both low and high frequency amplitudes were smaller in patients with atrial septal defect, both before and after operation, than in the controls, but there were no significant changes in amplitude with operation. Before operation $\mathbf{R R}$ interval standard deviations were low in accord with the lower preoperative spectral amplitudes in this group. Variability in the RR interval as seen in the standard deviations after operation was normal in contrast with the persistently low spectral amplitudes after operation. The low postoperative spectral amplitude may indicate residual autonomic abnormalities which later postoperative studies might clarify. In the present study, the considerable scatter of amplitude values within each of our groups permits only tentative conclusions.

Atrial septal defect in children is associated with retention of considerable variability of the heart rate, although it is less than for normal children. Closure of the atrial septal defect is associated with an: increase to normal variability. The possibility ofs abnormalities of autonomic control merits furthero study.

We thank Dr P Saul for his help in revising the pape $\frac{T_{2}}{2}$ and for suggestions on the methods and mechanisms We also thank Dr A E Marble, Dr D G Human, Dr J A Armour, Dr D L Roy, Ms E Jones, and Ms MP Langdon for help in preparing the paper.

\section{References}

1 Davies LG, Fotiades B. Sinus arrhythmia:observations in atrial septal defect and normal subjects [Abstract] Br Heart J 1960;22:301.

2 Finley JP, Nugent ST. Periodicities in respiration and heart rate in newborns. Can J Physiol Pharmaco 1983;61:329-35.

3 Wolf HK, MacInnis PJ, Stock S, Helppi RK, Rauta $\stackrel{\text { - }}{-}$ harju PM. Computer analysis of rest and exerciseo electrocardiograms. Comput Biomed Res 1972;5 329-46.

4 Finley JP, Hamilton R, MacKenzie MG. Heart rate response to tilting in newborns in quiet and active sleep. Biol Neonate 1984;45:1-10.

5 Schamroth L. The disorders of cardiac rhythm. Oxford Blackwell, 1971:20.

6 Finley JP, Nugent ST, Hellenbrand W. Heart rate variability in children: spectral analysis of develop윽 mental changes between 5 and 24 years. Can J Physiof Pharmacol 1987;65:2048-52.

7 Melcher A. Respiratory sinus arrhythmia in man: a. study in heart regulating mechanisms. Acta Physio Scand 1976;suppl 435.

8 Levin AR, Spach MS, Boineau JP, Canent RV Jr, CapB MP, Jewett PH. Atrial pressure-flow dynamics in atrial septal defects (secundum type). Circulation 1968;37:476-88.

9 Satomi G, Nakazawa M, Takao A, et al. Blood flow pattern of the interatrial communication in patient? with complete transposition of the great arteries: pulsed Doppler echocardiographic study. Circulatio 1986;73:95-9.

10 Pomeranz B, MacAulay RJB, Caudill MA, et al. Assess ment of autonomic function in humans by heart rate spectral analysis. Am J Physiol 1985;248:H151-3.

11 Pagani M, Lombardi F, Guzzetti S, et al. Power spectraf analysis of heart rate and arterial pressure variabilities as a marker of sympatho-vagal interaction in man an conscious dog. Circ Res 1986;59:178-93. 